\title{
Validation of minor species of the MIPAS2D database
}

\author{
ENZO PAPANDREA ${ }^{1, *}$, STEFANO CASADIO ${ }^{2}$, ENRICO \\ ARNONE $^{3}$, MASSIMO CARLOTTI ${ }^{1}$, ELISA CASTELLI ${ }^{3}$, \\ MARTA DE LAURENTIS ${ }^{2}$, BIANCA MARIA DINELLI ${ }^{3}$ \\ ${ }^{1}$ Dipartimento di Chimica Industriale "Toso Montanari", \\ Università di Bologna, Italy \\ ${ }^{2}$ IDEAS Serco S.p.A., Frascati (Roma), Italy \\ ${ }^{3}$ Istituto Scienze dell' Atmosfera e del Clima, ISAC-CNR, \\ Bologna, Italy \\ enzo.papandrea@unibo.it
}

\section{INTRODUCTION}

$\mathrm{T}$ he MIPAS2D [Dinelli et al., 2010] database has been developed applying the tomographic analysis technique GMTR. (Geo-fit MultiTarget Retrieval) [Carlotti et al., 2006] to measurements acquired in the nominal observation mode of the complete (2002-2012) MIPAS (Michelson Interferometer for Passive Atmosphere Sounding) [Fischer et al., 2008] mission. The MIPAS nominal observation mode is the reference and most commonly adopted mode of observation used in the first (2002-2004) and second (2005-2012) parts of the MIPAS mission (see Sect. II): although different limb patterns have been adopted in the two periods the database has been developed on a single vertical-horizontal grid. The GMTR algorithm enables the vertical distribution of a variety of atmospheric trace gases to be obtained. MIPAS2D version 2.3 adopted in this work contains 2-D atmospheric fields of pressure, temperature and VMRs (volume mixing ratios) of $\mathrm{H}_{2} \mathrm{O}, \mathrm{O}_{3}, \mathrm{HNO}_{3}, \mathrm{CH}_{4}, \mathrm{~N}_{2} \mathrm{O}, \mathrm{NO}_{2}, \mathrm{~N}_{2} \mathrm{O}_{5}$, $\mathrm{ClONO}_{2}, \mathrm{CFC}-11$, and CFC-12 on a fixed altitude/latitude grid for the full MIPAS mission. The complete validation exercise of the database is in progress. Here we report the comparison of MIPAS2D data for CFC-11, CFC-12 and $\mathrm{ClONO}_{2}$ with ACE (Atmospheric Chemistry Experiment)-FTS (Fourier Transform Spectrometer) [Bernath et al., 2005] data $^{1}$. For the purpose we used ACE Level 2 data version $2.2+$ updates. The ACE data consists of altitude profiles of temperature, atmospheric extinction and 14 atmospheric trace gas species.

This work focuses on chlorine-related products of the MIPAS2D database because they have outstanding importance in the understanding of key atmospheric processes and were previously considered by Papandrea et al. [2010], Kiefer et al. [2010] and by Arnone et al. [2013].

Man-made chlorofluorocarbons (CFCs) have been widely used in the past decades and then replaced with substitutes such as hydrochlorofluorocarbons (HCFCs). Transport of these long-lived compounds to the stratosphere leads to their photo-dissociation, with release of chlorine atoms that are strongly reactive and affect the stratospheric chemical

${ }^{1}$ This work has been performed in the frame of the MIPAS Quality Working Group activities. 
[2010], Kiefer et al. [2010] and by Arnone et al. [2013].

Man-made chlorofluorocarbons (CFCs) have been widely used in the past decades and then replaced with substitutes such as hydrochlorofluorocarbons (HCFCs). Transport of these long-lived compounds to the stratosphere leads to their photo-dissociation, with release of chlorine atoms that are strongly reactive and affect the stratospheric chemical composition. Among all the CFCs, the most used ones are $\mathrm{CCl}_{3} \mathrm{~F}$ (CFC-11) and $\mathrm{CCl}_{2} \mathrm{~F}_{2}$ (CFC-12), with the 2008 mean tropospheric concentrations of 245 and 535 pptv respectively [WMO Report Nr. 52, 2011]. The annual mean mixing ratio of $\mathrm{CFC}-11$ decreased at a rate of $2.0 \pm 0.6 \mathrm{ppt} / \mathrm{yr}$ from 2007 to 2008 . The global atmospheric mixing ratio of CFC12, which accounts for about one-third of the current atmospheric chlorine load, decreased for the first time in the time span from 2005 to 2008 and by mid-2008 had declined by $1.3 \%$ $(7.1 \pm 0.2 \mathrm{ppt})$ from the peak levels observed during 2000-2004. Chlorine nitrate $\left(\mathrm{ClONO}_{2}\right)$ is a major temporary reservoir gas of chlorine in the stratosphere. It plays an important role in the processes of ozone depletion [Brasseur and Solomon, 2005, and references therein]. The partitioning between active (ozone destroying) chlorine species like $\mathrm{Cl}$ and $\mathrm{ClO}$ and their ozone inactive reservoir gases $\mathrm{ClONO}_{2}$ and $\mathrm{HCl}$ controls the amount of polar ozone depletion through chlorine catalytic cycles. Heterogeneous chemistry on polar stratospheric clouds particles converts the chlorine reservoirs $\mathrm{ClONO}_{2}$ and $\mathrm{HCl}$ into $\mathrm{Cl}_{2}$. In the sunlit Antarctic spring, chlorine molecules are converted into active radicals such as $\mathrm{Cl}$ and $\mathrm{ClO}$, which destroy most of the vortex ozone at $14-20 \mathrm{~km}$. CFC-11 and CFC-12 are diurnally stable molecules, and therefore they are easily comparable with correlative measurements. On the contrary, the species $\mathrm{ClONO}_{2}$ shows diurnal variability. This means that, when comparing measurements coming from different instruments, the different acquisition time must be kept into consideration. Preliminary results are reported here.

\section{ENVISAT-MIPAS DATA}

MIPAS [Fischer et al., 2008] was a limbscanning spectrometer developed by the European Space Agency (ESA) for the study of the atmospheric composition deployed on board the ENVISAT satellite on a nearly polar orbit. It measured the infra-red atmospheric emission with limb viewing geometry from 4.1 to $14.5 \mu \mathrm{m}\left(685-2410 \mathrm{~cm}^{-1}\right)$ mostly over the altitude range $6-70 \mathrm{~km}$. MIPAS acquired atmospheric spectra from July 2002 to April 2012 with different spectral and spatial resolutions: at $0.025 \mathrm{~cm}^{-1}$ (full resolution measurements) at the beginning of the mission to March 2004 and since January 2005 at $0.0625 \mathrm{~cm}^{-1}$ (optimized resolution measurements). MIPAS measured both daytime and nighttime with a global coverage of the Earth, into a sunsynchronous polar orbit with equatorial local crossing time of approximately 10:00 p.m. (ascending node). In a nominal (NOM) orbit of the optimized resolution period, MIPAS limbscans covered the atmosphere from about 6 to $70 \mathrm{~km}$ in 27 views (every $1.5 \mathrm{~km}$ from 6 to 21 $\mathrm{km}$, every $2 \mathrm{~km}$ from 21 to $31 \mathrm{~km}$, every $3 \mathrm{~km}$ from 31 to $46 \mathrm{~km}$, and every $4 \mathrm{~km}$ from 46 to 70 $\mathrm{km})$, while in the full resolution period the limb scans were made of 17 views (from 6 to 42 $\mathrm{km}$ at $3 \mathrm{~km}$ steps then at 47, 52, 60 and $68 \mathrm{~km}$ ). ESA provides Level 2 retrievals of the NOM mode measurements as described in [Ridolfi et 
al., 2000; Raspollini et al., 2013]. The ESA retrieval code makes use of the Global-fit approach [Carlotti, 1988]. A collaboration between the University of Bologna and the ISACCNR of Bologna led to the development of an innovative retrieval code for MIPAS observations, called GMTR [Carlotti et al., 2006], using both the Geo-fit approach [Carlotti et al., 2001] and the Multi-Target Retrieval (MTR) functionality [Dinelli et al., 2003]. GMTR performs tomographic retrievals with the possibility to simultaneously retrieve interfering species. The tomographic approach enables the observations collected along a whole orbit to be analysed simultaneously. GMTR operates a 2-D discretization of the atmosphere, therefore enabling the horizontal atmospheric structures to be modelled. [Carlotti et al., 2001]. In GMTR each limb observation contributes to determine the unknown quantity at a number of different locations among those spanned by its line of sight rather than only at the tangent points as in standard 1-D retrievals. Using GMTR, a Level 2 database has been obtained (MIPAS2D [Dinelli et al., 2010]) of 2-D fields of pressure, temperature and VMR profiles of atmospheric constituents. Each target has been retrieved at fixed latitudes on an altitude grid that corresponds to the nominal sampling of the MIPAS full resolution mission (from 6 to $68 \mathrm{~km}$, with 3 $\mathrm{km}$ steps up to $42 \mathrm{~km}$ and then at the altitudes of $47,52,60$ and $68 \mathrm{~km}$ ). The retrievals make use of a priori information that, for the species considered in this paper, is derived from climatological data [Remedios et al., 2007] and are operated on selected microwindows, i.e. narrow spectral interval (less than $3 \mathrm{~cm}^{-1}$ wide) containing major information on the target parameters to be retrieved.

\section{ACE-FTS DATA}

ACE [Bernath et al., 2005] is a Canadian satellite mission aimed at the study of the Earth's atmosphere using the limb scanning technique. It was launched into a high inclination $\left(74^{\circ}\right)$ circular low orbit $(650 \mathrm{~km})$ on 12 August 2003. Primarily ACE operates in solar occultation providing altitude profiles (typically 10-100 km) for temperature, pressure, and the VMRs for several atmospheric species. The ACE instrument is a high spectral resolution $\left(0.02 \mathrm{~cm}^{-1}\right)$ limbscanning FTS that measures between 2.2 and $13.3 \mu \mathrm{m}\left(750-4400 \mathrm{~cm}^{-1}\right)$, with high signal-tonoise ratios, in the altitude range from 5 (or cloud top) to $150 \mathrm{~km}$. The ACE orbit gives global Earth coverage, useful to study a wide range of atmospheric processes.

The ACE-FTS measures limb sequences of atmospheric absorption spectra during sunrise and sunset. Level 2 data are retrieved by a non-linear least squares global fitting technique [Carlotti, 1988] that operates on selected microwindows (generally $0.3-1 \mathrm{~cm}^{-1}$ ) [Boone et al., 2005]. The analysis approach does not employ constraints from a priori information (i.e. optimal estimation). First pressure and temperature, as a function of altitude, are determined through the analysis of $\mathrm{CO}_{2}$ lines, then VMRs are retrieved. The ACE Level 2 database used here is version $2.2+$ updates and is available at http://www.ace.uwaterloo.ca.

\section{COLLOCATION AND FILTERING CRITERIA}

The MIPAS2D and ACE-FTS datasets obtained in the analysis of the measurements from 2005 to 2009 have been used for this validation exercise. Only collocated data have been 

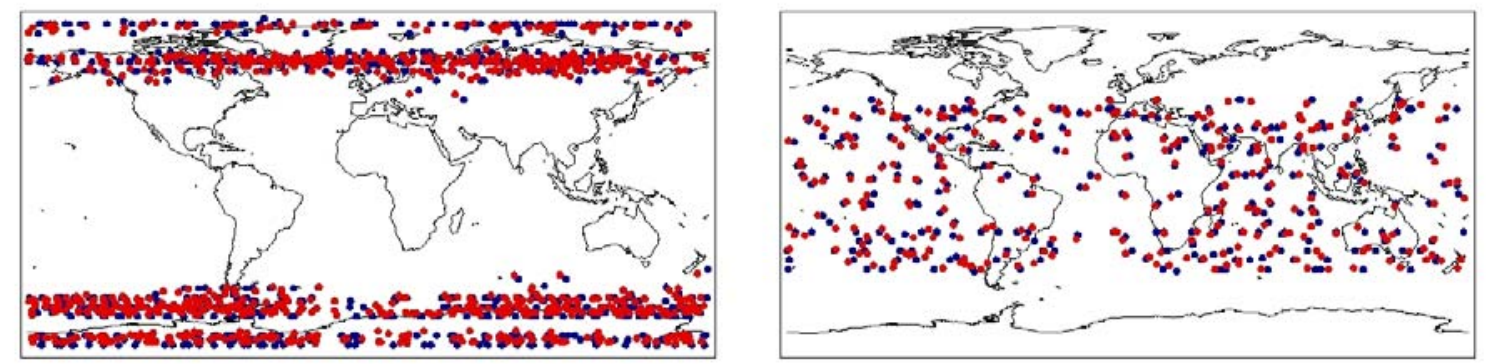

Figure 1. MIPAS2D (red) and ACE-FTS (blue) geolocations of the coincidences for the polar (830 collocations, left panel) and the trp-midlat (260 collocations, right panel) regions.

compared: coincidence criteria were determined on the basis of spatial (by distance) and time limits.

For all the considered species spatial collocation was assumed when the maximum distance between MIPAS2D and ACE-FTS measurements was $\leq 500 \mathrm{~km}$. The latitude domain has been divided into two regions characterized by different time windows:

- polar: latitudes $<-60^{\circ}$ and $>60^{\circ}, 2$ hours time window

- tropical-mid latitudes (trp-midlat): $-60^{\circ}<$ latitude $<60^{\circ}, 6$ hours time window

The reason for increasing the time window in the trp-midlat is to have a statistically suitable number of coincidences. In total we found 830 collocations for the polar regions and 260 for the trp-midlat regions. We then applied a filter to both MIPAS2D and ACE-FTS data in order to rejects single $\mathrm{VMR}$ values having an estimated standard deviation greater than $30 \%$. This threshold has been chosen with dedicated tests on the basis of a trade-off between the amount of values kept in the statistics and the quality of the data. In case of multiple coincidence (more than one
MIPAS2D match every ACE-FTS profile), we averaged the MIPAS2D results in order to obtain only one profile.

The datasets have been compared in the pressure domain instead than in the altitude domain. This choice has been done in order to avoid possible additional MIPAS2D errors introduced by the different assumptions made by the analysis systems regarding the pressure to altitude transformation. Therefore MIPAS2D profiles were logarithmically interpolated on the pressure levels of ACE-FTS before the comparison. In the comparison we did not smooth the profiles taking into account the averaging kernels. This is an acceptable approximation because the difference in the vertical resolution of the two datasets is small (about $4 \mathrm{~km}$ for ACE-FTS, $4-5 \mathrm{~km}$ for MIPAS2D), leading to similar smoothing errors.

The two panels of Figure 1 show the geolocations of the data used in the comparison: the red dots represents the geolocation of MIPAS2D data and the blue dots the geolocations of ACE data.

\section{RESULTS}



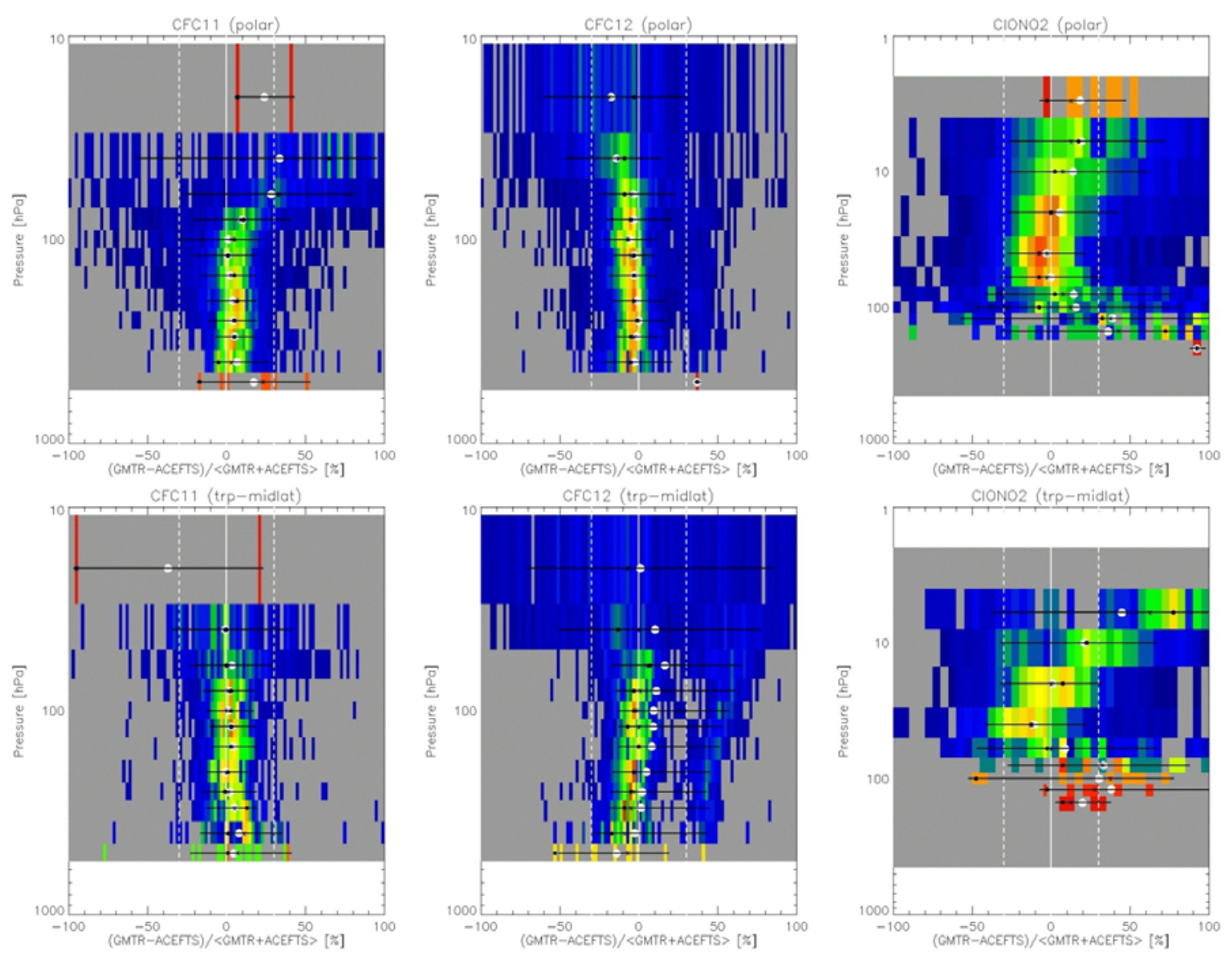

Figure 2. From left to right: CFC-11, CFC-12, $\mathrm{ClONO}_{2} \mathrm{MIPAS} 2 \mathrm{D}-\mathrm{ACE}$ differences computed as (1) for polar (top) and trp-midlat (bottom) regions. In each panel the distribution of the differences is indicated using white circles (mean), star symbols (median), and black dots (mode). The horizontal black lines indicate the $80 \%$ percentile. The colour (arbitrary) scale indicates the number density of samples having same difference values for each pressure layer from blue to red in increasing order (grey = no data).

Fractional differences between the VMRs from MIPAS2D and ACE-FTS have been computed using the following expression:

$$
\text { Diff }=2 \frac{M I P A S 2 D-A C E}{M I P A S 2 D+A C E}
$$

and divided into fixed pressure bins for both the polar and the trp-midlat regions and for all the considered species. In the analysis the polar regions have been subdivided into ACEFTS sunrise (sr) and sunset (ss) cases as some differences were observed between them. Figure 2 shows the distribution of the frequency of the differences (mean, mode and median) in each pressure interval, for CFC-11, CFC-12, and $\mathrm{ClONO}_{2}$, computed with expression (1) for both the polar (top) and the trp-midlat (bottom) regions.

In order to simplify the interpretation of the plots in Table 1 we report the median of the differences (along with the number of samples) at each level of pressure. 
Table 1: Percentage median of the differences between MIPAS2D and ACE-FTS. The parenthetical values are the number of coincidences.

\begin{tabular}{cllllll}
\hline Species & \multicolumn{2}{c}{ CFC-11 } & \multicolumn{2}{c}{ CFC-12 } & \multicolumn{2}{c}{$\mathrm{ClONO}_{2}$} \\
\hline Pressure (hPa) & Polar & Trp-midlat & Polar & Trp-midlat & Polar & Trp-midlat \\
\hline 3 & & & & & $12(10)$ & \\
\hline 6 & & & & & $12(405)$ & $62(119)$ \\
\hline 10 & & & & & $7(968)$ & $22(557)$ \\
\hline 20 & $7(2)$ & $-95(2)$ & $-19(443)$ & $-7(528)$ & $0(1333)$ & $0(670)$ \\
\hline 40 & $45(141)$ & $-1(170)$ & $-13(913)$ & $0(595)$ & $-2(1128)$ & $-12(356)$ \\
\hline 60 & $33(463)$ & $1(349)$ & $-5(864)$ & $5(446)$ & $-2(743)$ & $0(117)$ \\
\hline 80 & $9(586)$ & $1(285)$ & $-5(759)$ & $1(360)$ & $7(350)$ & $32(28)$ \\
\hline 100 & $3(557)$ & $0(214)$ & $-7(693)$ & $-1(269)$ & $12(192)$ & $37(10)$ \\
\hline 120 & $1(653)$ & $3(212)$ & $-5(780)$ & $0(268)$ & $37(68)$ & $27(7)$ \\
\hline 150 & $3(846)$ & $3(276)$ & $-3(1012)$ & $0(359)$ & $42(44)$ & $12(4)$ \\
\hline 200 & $5(791)$ & $0(216)$ & $-3(977)$ & $-3(264)$ & $92(1)$ & \\
\hline 250 & $5(469)$ & $1(160)$ & $-1(582)$ & $-3(193)$ & & \\
\hline 300 & $5(353)$ & $5(111)$ & $-3(420)$ & $-5(128)$ & & \\
\hline 400 & $3(129)$ & $11(68)$ & $-5(140)$ & $-9(67)$ & & \\
\hline 500 & $23(8)$ & $7(17)$ & $37(1)$ & $-7(12)$ & & \\
\hline
\end{tabular}

Table 2: Range of the bias (considered as percentage median of the differences in a statistically meaningful pressure range) between MIPAS2D and ACE-FTS.

\begin{tabular}{cllll}
\hline Species & Polar (sr) [\%] & Polar (ss) [\%] & Polar (all) [\%] & Trp-midlat (all) [\%] \\
\hline CFC-11 & $3-5(+)$ & $0-9(+)$ & $1-5(+)$ & $0-5(+)$ \\
\hline CFC-12 & $1-5(-)$ & $3-9(-)$ & $1-7(-)$ & $1-9(-)$ \\
\hline $\begin{array}{c}\mathrm{ClONO}_{2} \\
(60-20 \mathrm{hPa} \text { range })\end{array}$ & \pm 2 & $0-2(-)$ & $0-2(-)$ & $0-12(-)$ \\
\hline
\end{tabular}

We notice in Figure 2 that CFC-12 has a double distribution: one close to zero and the other close to $30-40 \%$ (polar) or $40-50 \%$ (trp-midlat). This non-physical behaviour is caused by some "anomalous" ACE-FTS profiles. These VMRs are indeed too low and cause the second distribution around $30-50 \%$ when computing the difference between MIPAS2D and ACEFTS profiles. The occurrence of this problem and the dissimilarity between "normal" and "anomalous" ACE-FTS values are much higher in case of CFC-12 than in the other species. However, even if this problem causes distortions to the arithmetic average, the median is only marginally affected and the mode is totally unaffected. We point out that hereafter we discuss the biases only in terms of median of the differences therefore our conclusions are almost independent from the side distribution. 
We summarize the biases that have been found in each atmospheric region for each target in Table 2 .

In general, considering both sunrise and sunset ACE-FTS measurements, MIPAS2D CFC-11 shows a small positive bias (1-5\%) between 400 and $100 \mathrm{hPa}(8-18 \mathrm{~km})$ in the polar regions and a similar bias (0 to $5 \%$ ) between 300 and $40 \mathrm{hPa}(10-24 \mathrm{~km})$ in the trpmidlat. MIPAS2D CFC-12 generally shows a negative bias $(1-7 \%)$ from 400 to $60 \mathrm{hPa}(8-21$ $\mathrm{km})$ in the polar regions, and a similar one (1$9 \%)$ in the trp-midlat from 400 to $20 \mathrm{hPa}(8-29$ $\mathrm{km})$. For these molecules the variability is lower than $15 \%$ in the polar regions and lower than $20 \%$ in the trp-midlat. ACE-FTS CFC- 11 and CFC-12 have been previously compared with a single FIRS-2 flight and with zonal mean MkIV balloon data [Mahieu et al., 2008]. These comparisons show that the ACE-FTS vertical distributions are reasonably good for both the species, although they generally seem to be lower in most of the altitude range, i.e. between 12 and $20 \mathrm{~km}(230-70 \mathrm{hPa})$. However, this analysis was performed with a limited number of coincidences. In particular, for CFC11, below $16 \mathrm{~km}(130 \mathrm{hPa})$ differences were smaller than $10 \%$ while above they increased with increasing altitude, up to $87 \%$ at $19 \mathrm{~km}$ $(85 \mathrm{hPa})$ w.r.t. FIRS-2, below $12 \mathrm{~km}(230 \mathrm{hPa})$ differences were about $20 \%$ and above of the order of $10 \%$ w.r.t MkIV. For CFC-12, they found below $20 \mathrm{~km}(73 \mathrm{hPa}$ ) a positive bias (up to $50 \%$ ) when comparing ACE-FTS with FIRS2 and a negative bias (up to $160 \%$ at $24 \mathrm{~km}$ or $40 \mathrm{hPa}$ ) above. In the inter-comparison with MkIV the findings were similar to CFC-11 but the entity of the bias was smaller (up to $10 \%$ ). MIPAS2D $\mathrm{ClONO}_{2}$ shows a very small negative bias in the trp-midlat (0-2\%) between
60 and $20 \mathrm{hPa}(21-29 \mathrm{~km})$ and a larger one in the polar regions $(0-12 \%)$ between 60 and 20 $\mathrm{hPa}(21-29 \mathrm{~km}) \cdot \mathrm{ClONO}_{2}$ comparison has a larger $(>30 \%)$ variability. This is due to its diurnal variability that makes the measured VMR highly dependent from the acquisition time. Wolff et al. [2008] reported a good agreement between ACE-FTS and MIPAS IMK-IAA retrievals. The mean absolute differences they found were typically within $\pm 0.01 \mathrm{ppbv}$ and reached not more than -0.04 ppbv $( \pm 1 \%)$ for $130-27 \mathrm{hPa}(16-27 \mathrm{~km})$. The $\mathrm{ClONO}_{2}$ differences we are reporting can be mostly explained by the time mismatch. Above $20 \mathrm{hPa}(29 \mathrm{~km})$, the differences tend to increase with altitude (even if is not possible to draw clear conclusions because of the large variability). A bias at high altitudes has been also observed by Höpfner et al. [2007] when comparing MIPAS IMK-IAA retrievals with ACE-FTS. They successfully removed the bias using a chemical transport model to correct MIPAS data for the time mismatch demonstrating that the reported behaviour is induced by photochemistry.

\section{CONCLUSIONS}

MIPAS2D 2-D fields of $\mathrm{ClONO}_{2}$, CFC-11, and CFC-12, obtained applying the tomographic code GMTR to measurements acquired in the nominal observation mode of the complete MIPAS mission have been compared with ACE-FTS data. The comparison was restricted to data measured from 2005 to 2009.

MIPAS2D CFC-11 shows a generally small positive bias ranging from 1 to $5 \%, C F C-12$ a negative bias ranging from 1 to $9 \%$ and $\mathrm{ClONO}_{2}$ a very small negative bias in the tropical-mid latitude (0-2\%). This bias becomes larger in the polar regions $(0-12 \%)$. These 
general conclusion are valid within the pressure range $300-100 \mathrm{hPa}(10-18 \mathrm{~km})$ for the two chlorofluorocarbons and within the more restricted pressure interval of $60-20 \mathrm{hPa}(21-29$ $\mathrm{km}$ ) for the chlorine nitrate.

In addition of the reasons that are usually cause of biases, some of the differences may be here explained by the two different retrieval approaches, ACE-FTS uses a 1-D approach while the MIPAS2D data have been obtained using a 2-D code. The 1-D retrievals may be indeed affected by systematic errors especially when the horizontal gradients of the atmosphere are strong [e.g. Kiefer et al., 2010; Puksite et al., 2008].

We are planning to extend the analysis over a longer time period and to increase the number of species in the comparison.

\section{REFERENCES}

[Arnone et al., 2013] Arnone, E., E. Castelli, E. Papandrea, M. Carlotti, and B.M. Dinelli (2012). Extreme ozone depletion in the 20102011 Arctic winter stratosphere as observed by MIPAS/ENVISAT using a 2-D tomographic approach, Atmos. Chem. Phys., 12, 9149-9165.

[Brasseur and Solomon, 2005] Brasseur, G. P. and Solomon, S. (2005). Aeronomy of the Middle Atmosphere, $3^{\text {rd }}$ revised and enlarged edition, Springer.

[Bernath et al., 2005] Bernath, P.F., C.T. McElroy, M.C. Abrams, C.D. Boone, M. Butler, C. Camy-Peyret, M. Carleer, C. Clerbaux, P.-F. Coheur, R. Colin, P. DeCola, M. DeMazie, J.R. Drummond, D. Dufour, W.F.J. Evans, H. Fast, D. Fussen, K. Gilbert, D.E. Jennings, E.J. Llewellyn, R.P. Lowe, E. Mahieu, J.C. McConnell, M. McHugh, S.D. McLeod, R. Michaud, C. Midwinter, R. Nassar, F. Nichitiu, C. Nowlan, C.P. Rinsland, Y.J. Rochon, N. Rowlands, K. Semeniuk, P. Simon, R. Skelton,
J.J. Sloan, M.-A. Soucy, K. Strong, P. Tremblay, D. Turnbull, K.A. Walker, I. Walkty, D.A. Wardle, V. Wehrle, R. Zander, and J. Zou. (2005). Atmospheric Chemistry Experiment (ACE): Mission overview. Geophys. Res. Lett., 31, L15S01.

[Boone et al., 2005] Boone, C.D., R. Nassar, ,K.A. Walker,Y. Rochon,S.D. Mcleod, C.P. Rinsland, and P.F. Bernath (2005). Retrievals for the Atmo-spheric Chemistry Experiment Fourier-Transform Spectrometrer, Appl. Opt., 44, 7218-7231.

[Carlotti, 1988] Carlotti, M. (1988). Global-fit approach to the analysis of limb-scanning atmospheric measurements, Appl. Opt., 27, No. 15, 3250.

[Carlotti et al., 2001] Carlotti, M., B.M. Dinelli, P. Raspollini, and M. Ridolfi (2001). Geo-fit approach to the analysis of satellite limbscanning measurements. Appl. Opt., 40, 18721885.

[Carlotti et al., 2006] Carlotti, M., G. Brizzi, E. Papandrea, M. Prevedelli, M. Ridolfi, B.M. Dinelli, and L. Magnani (2006). GMTR: Twodimensional geo-fit multitarget retrieval model for Michelson Interferometer for Passive Atmospheric Sounding/Environmental Satellite observations. Appl. Opt., 45, 716-727. [Dinelli et al., 2003] Dinelli, B.M., D. Alpaslan, M. Carlotti, L. Magnani, M. Ridolfi (2003). Multi-Target Retrieval (MTR): the simultaneous retrieval of pressure, temperature and volume mixing ratio from limb-scanning atmospheric measurements. J. Quant. Spec. Radiat. Transfer, 84, 141-157.

[Dinelli et al., 2010] Dinelli, B.M., E. Arnone, G. Brizzi, M. Carlotti, E. Castelli, L. Magnani, E. Papandrea, M. Prevedelli, and M. Ridolfi (2010). The MIPAS2D database of MIPAS/ENVISAT measurements retrieved with a Multi-Target 2-dimensional 
tomographic approach. Atmos. Meas. Tech., 2, 355-374.

[Fischer et al., 2008] Fischer, H., M. Birk, C. Blom, B. Carli, M. Carlotti, T. von Clarmann, L. Delbouille, A. Dudhia, D. Ehhalt, M. Endemann, J.M. Flaud, R. Gessner, A. Kleinert, R. Koopman, J. Langen, M. López-Puertas, P. Mosner, H. Nett, H. Oelhaf, G. Perron, J. Remedios, M. Ridolfi, G. Stiller, R. Zander. (2008). MIPAS: an instrument for atmospheric and climate research. Atmos. Chem. Phys., 8, 2151-2188.

[Höpfner et al., 2007] Höpfner, M., T. von Clarmann, H. Fischer, B. Funke, N. Glatthor, U. Grabowski, S. Kellmann, M. Kiefer, A. Linden, M. Milz, T. Steck, G.P. Stiller, P. Bernath, C.E. Blom, Th. Blumenstock, C. Boone, K. Chance, M.T. Coffey, F. FriedlVallon, D. Griffith, J.W. Hannigan, F. Hase, N. Jones, K.W. Jucks, C. Keim, A. Kleinert, W. Kouker, G.Y. Liu, E. Mahieu, J. Mellqvist, S. Mikuteit, J. Notholt, H. Oelhaf, C. Piesch, T. Reddmann, R. Ruhnke, M. Schneider, A. Strandberg, G. Toon, K.A. Walker, T. Warneke, G. Wetzel, S. Wood, and R. Zander (2007). Validation of MIPAS $\mathrm{ClONO}_{2}$ measurements. Atmos. Chem. Phys., 7, 257-281.

[Kiefer et al., 2010] Kiefer, M., E. Arnone, A. Dudhia, M. Carlotti, E. Castelli, T. von Clarmann, B.M. Dinelli, A. Kleinert, A. Linden, M. Milz, E. Papandrea, and G. Stiller (2010). Impact of temperature field inhomogeneities on the retrieval of atmospheric species from MIPAS IR limb emission spectra, Atmos. Meas. Tech., 3, 1487-1507.

[Mahieu et al., 2008] Mahieu, E., P. Duchatelet, P. Demoulin, K.A. Walker, E. Dupuy, L. Froidevaux, C. Randall, V. Catoire, K. Strong, C.D. Boone, P.F. Bernath, J.-F. Blavier, T. Blumenstock, M. Coffey, M. De Mazière, D. Griffith, J. Hannigan, F. Hase, N. Jones, K.W. Jucks, A. Kagawa, Y. Kasai, Y. Mebarki, S.
Mikuteit, R. Nassar, J. Notholt, C.P. Rinsland, C. Robert, O. Schrems, C. Senten, D. Smale, J. Taylor, C. Tétard, G.C. Toon, T. Warneke, S.W. Wood, R. Zander, and C. Servai (2008). Validation of ACE-FTS v2.2 measurements of $\mathrm{HCl}, \mathrm{HF}, \mathrm{CCl}_{3} \mathrm{~F}$ and $\mathrm{CCl}_{2} \mathrm{~F}_{2}$ using space-, balloon- and ground-based instrument observations. Atmos. Chem. Phys., 8, 61996221.

[Papandrea et al., 2010] Papandrea, E., E. Arnone, G. Brizzi, M. Carlotti, E. Castelli, B.M. Dinelli, and M. Ridolfi (2010). Twodimensional tomographic retrieval of MIPAS/ENVISAT measurements of ozone and related species. Int. J. Rem. Sens., 31: 2, 477-483.

[Puķīte et al., 2008]. Puķite, J., S. Kühl, T. Deutschmann, U. Platt, and T. Wagner (2008). Accounting for the effect of horizontal gradients in limb measurements of scattered sunlight, Atmos. Chem. Phys., 8, 3045-3060.

[Raspollini et al., 2013] Raspollini, P., B. Carli, M. Carlotti, S. Ceccherini, A. Dehn, B.M. Dinelli, A. Dudhia, J.-M. Flaud, M. LópezPuertas, F. Niro, J.J. Remedios, M. Ridolfi, H. Sembhi, L. Sgheri, and T. von Clarmann (2013).Ten years of MIPAS measurements with ESA Level 2 processor V6 - Part I: retrieval algorithm and diagnostics of the products. Atmos. Meas. Tech. Discuss., 6, 461-518.

[Remedios et al., 2007] Remedios, J. J., R. J. Leigh, A.M. Waterfall, D.P. Moore, H. Sembhi, I. Parkes, J. Greenhough, M.P. Chipperfield, and D. Hauglustaine (2007). MIPAS reference atmospheres and comparisons to V4.61/V4.62 MIPAS level 2 geophysical data sets, Atmos. Chem. Phys. Discuss., 7, 9973-10017.

[Ridolfi et al., 2000] Ridolfi, M., B. Carli, M. Carlotti, T. von Clarmann, B.M. Dinelli, A. Dudhia, J.-M. Flaud, M. Höpfner, P.E. Morris, P. Raspollini, G. Stiller, and J.W. Robert (2000). Optimized Forward and Retrieval Scheme for 
MIPAS Near-Real-Time Data Processing, Appl. Opt., 39, 1323-1340.

[Wolff et al. , 2008] Wolff, M.A., T. Kerzenmacher, K. Strong, K.A. Walker, M. Toohey, E. Dupuy, P.F. Bernath, C.D. Boone, S. Brohede, V. Catoire, T. Von Clarmann, M. Coffey, W.H. Daffer, M. De Mazière, P. Duchatelet, N. Glatthor, D.W.T. Griffith, J. Hannigan, F. Hase, M. Höpfner, N. Huret, N. Jones, K. Jucks, A. Kagawa, Y. Kasai, I. Kramer, H. Küllmann, J. Kuttippurath, E. Mahieu, G. Manney, C.T. McElroy, C. McLinden, Y. Mébarki, S. Mikuteit, D. Murtagh, C. Piccolo, P. Raspollini, M. Ridolfi, R. Ruhnke, M. Santee, C. Senten, D. Smale, C. Tétard, J. Urban, and S. Wood (2008). Validation of $\mathrm{HNO}_{3}, \mathrm{ClONO}_{2}$, and $\mathrm{N}_{2} \mathrm{O}_{5}$ from the Atmospheric Chemistry Experiment Fourier Transform Spectrometer (ACE-FTS). Atmos. Chem. Phys., 8, 3529-3562.

[WMO Report Nr. 52, 2011] WMO Report No. 52. (2011). Scientific Asses ${ }^{2}$ sment of Ozone Depletion: 2010. Global Ozone Research and Monitoring Project-Report No. 52, 516 pp., Geneva, Switzerland.

* Corresponding author: Enzo Papandrea, Dipartimento di Chimica Industriale "Toso Montanari", Università di Bologna, Italy, email: enzo.papandrea@unibo.it. 